\title{
DROPLETS FROM THE PLANKTON NET. XXII. -OBSERVATION ON A NINE-INDIVIDUAL CHAIN OF PEGEA CONFOEDERATA BICAUDATA (Q. \& G.)-
}

$\operatorname{AUTHOR}(S)$ :

Furuhashi, Kenzo; Tokioka, Takasi

\section{CITATION:}

Furuhashi, Kenzo ...[et al]. DROPLETS FROM THE PLANKTON NET. XXII. -OBSERVATION ON A NINE-INDIVIDUAL CHAIN OF PEGEA CONFOEDERATA BICAUDATA (Q. \& G.)-.

PUBLICATIONS OF THE SETO MARINE BIOLOGICAL LABORATORY 1966, 14(2): 117-122

\section{ISSUE DATE:}

1966-06-30

URL:

http://hdl.handle.net/2433/175433

RIGHT: 


\title{
DROPLETS FROM THE PLANKTON NET. XXII. OBSERVATION ON A NINE-INDIVIDUAL CHAIN OF PEGEA CONFOEDERATA BICAUDATA (Q. \& G. $)^{1)}$
}

\author{
KENZO FURUHASHI \\ Oceanogr. Secton, Japan Meteorological Agency \\ and
}

TAKASI TOKIOKA

Seto Marine Biological Laboratory

With 3 Text-figures

The first author happened to observe a live salp chain collectd by $\mathrm{Mr}$. Akira SANo of the Oceanographical Section of Japan Meteorological Agency on May 1, 1965, $23.00 \mathrm{~h}$, with a hand-net from the sea surface at St. I-7 of JEDS- 10 Cruise, $30^{\circ} 09^{\prime} \mathrm{N}$ and $136^{\circ} 56^{\prime} \mathrm{E}$. The chain consisted of nine aggregated forms of Pegea confoederata bicaudata (Quoy et GAIMARD) which were respectively provided with a pair of posterior protuberances, and this attracted his notice because the terminal individuals of the chain were significantly different from other chain individuals. Terminal individuals had the protuberances of remarkably different length, while others were furnished with protuberances of nearly the same length. Unfortunately, the chain individuals had been liberated from one another before any photograph of the complete chain was taken. Then, in order to ascertain the morphological difference between the terminal individuals and others, all of the released chain individuals were sent to the last author for more detailed examinations.

The nine individuals are respectively of the following body sizes and aspects :

1. $52 \mathrm{~mm}$ long terminal individual, with left posterior protuberance $11 \mathrm{~mm}$ long including $6 \mathrm{~mm}$ long terminal bulb and right posterior protuberance $30 \mathrm{~mm}$ long including $20 \mathrm{~mm}$ long terminal thread.

2. $59 \mathrm{~mm}$ long individual of Type $\mathrm{I}$, with left posterior protuberance $12 \mathrm{~mm}$ long including $4 \mathrm{~mm}$ long terminal bulb and right posterior protuberance $9 \mathrm{~mm}$ long including $3 \mathrm{~mm}$ long terminal bulb.

1) Contributions from the Seto Marine Biological Laboratory, No. 452.

Publ. Seto Mar. Biol. Lab., XIV (2), 117-122, $1966 . \quad$ (Article 8) 
3. $61 \mathrm{~mm}$ long individual of Type II, with left posterior protuberance $13 \mathrm{~mm}$ long including $5 \mathrm{~mm}$ long terminal bulb and right posterior protuberance $15 \mathrm{~mm}$ long including $4 \mathrm{~mm}$ long terminal bulb.

4. $61 \mathrm{~mm}$ long individual of Type $\mathrm{I}$, with left posterior protuberance $8 \mathrm{~mm}$ long including $3 \mathrm{~mm}$ long terminal bulb and right posterior protuberance $13 \mathrm{~mm}$ long including $4 \mathrm{~mm}$ long terminal bulb.

5. $63 \mathrm{~mm}$ long individual of Type II, with left posterior protuberance $15 \mathrm{~mm}$ long including $5 \mathrm{~mm}$ long terminal bulb and right posterior protuberance $13 \mathrm{~mm}$ long including $4 \mathrm{~mm}$ long terminal bulb.

6. $63 \mathrm{~mm}$ long individual of Type II, with left posterior protuberance $13 \mathrm{~mm}$ long including $5 \mathrm{~mm}$ long terminal bulb and right posterior protuberance $12 \mathrm{~mm}$ long including $3 \mathrm{~mm}$ long terminal bulb.

7. $65 \mathrm{~mm}$ individual of Type $\mathrm{I}$, with left posterior protuberance $20 \mathrm{~mm}$ long including $3 \mathrm{~mm}$ long terminal bulb and right posterior protuberance $15 \mathrm{~mm}$ long including $4 \mathrm{~mm}$ long terminal bulb.

8. $67 \mathrm{~mm}$ long individual of Type II, with left posterior protuberance $14 \mathrm{~mm}$ long including $5 \mathrm{~mm}$ long terminal bulb and right posterior protuberance $12 \mathrm{~mm}$ long including $3 \mathrm{~mm}$ long terminal bulb.

9. $73 \mathrm{~mm}$ long terminal individual, with left posterior protuberance $7 \mathrm{~mm}$ long including $3 \mathrm{~mm}$ long terminal bulb and right posterior protuberance $37 \mathrm{~mm}$ long including $27 \mathrm{~mm}$ long terminal thread.

Individuals of Type I (Fig. 1 Left) have the posterior protuberances directed obliquely forward, while in those of Type II (Fig. 1 Right) the protuberances are extended laterally. Terminal individuals (Fig. 2 Left) are fundamentally of Type II, but they have the right protuberance much longer than the left. In other individuals than terminal ones, the difference between left and right protuberances does not seem significant, and no positive relation can be found between the type and the length of the protuberances on either side. The differentiation of the types of the posterior protuberances might be or might not be related to the sinistral and dextral situation of the chain individuals; anyhow at present it is impossible for us to rearrange with certainty these nine released individuals to construct the former chain. Perhaps they were arranged as shown in Fig. 3.

No specialization is found in the morphology of the aggregated forms, except for the posterior protuberances which will be described later in detail. All individuals bear an embryo of advanced stage (Fig. 2 Right); three embryos were found, together with the distal part of the placenta, liberated from the mother body. Embryos are $4 \mathrm{~mm}$ in length, except in the smallest (terminal) individual, in which the embryo is $3.5 \mathrm{~mm}$ long. The placenta is an elongate spatulate structure up to $7 \mathrm{~mm}$ in length. It starts near the middle of the space between the body muscles III and IV on the right side and reaches the level of body muscle III increasing the breadth distally and ending in 
an obtusely truncate edge with a prominent depression at the middle. The embryo is situated with its atrial aperture toward the branchial aperture of the mother individual and with its ventral side towards the periphery of the mother body. The umbilical cord of a considerable length connects the point on the mid-ventral line at the anterior one-third of the embryo endostyle and the median depression at the distal end of the placenta. The elaeoblast

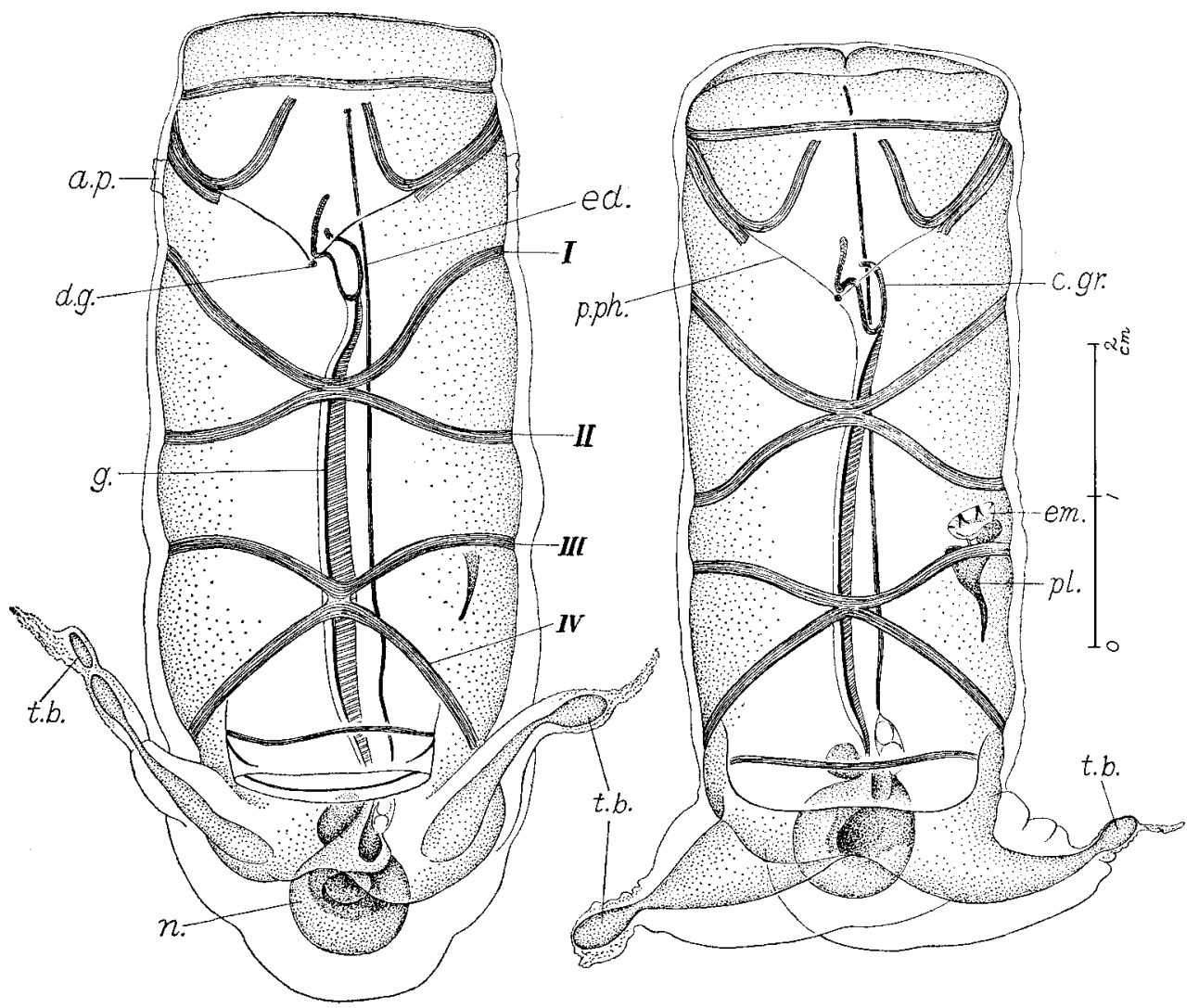

Fig. 1. Pegea confoederata bicaudata (Q. \& G.) greg. Left: No. 7 individual of Type I. Right : No. 3 individual of Type II. a.p.-attachment process, at.--atrial aperture, $c . g r$.ciliated groove, d.g.-dorsal ganglion, ed.-endostyle, el.-elaeoblast, em.-embryo, g.-gill, $m$.-body muscle, $n$.-nucleus, or.-oral aperture, $p l$--placenta, $p . p h$.-peripharyngeal band, $t . b$. - terminal bulb, thr.-terminal thread, $u$. c. - umbilical cord, $I-I V$-first to fourth body' muscles.

is very large, half as long as the embryo. The above-mentioned structures are quite the same as those of the typical form of the species.

The most noticeable feature on these chain individuals is the structure of the posterior protuberances. All short posterior protuberances consist of a stout basal portion and a short distal portion forming a terminal bulb (t.b. in figures) which is roughly elliptical or oval in outline, and 3 to $5 \mathrm{~mm}$ in 


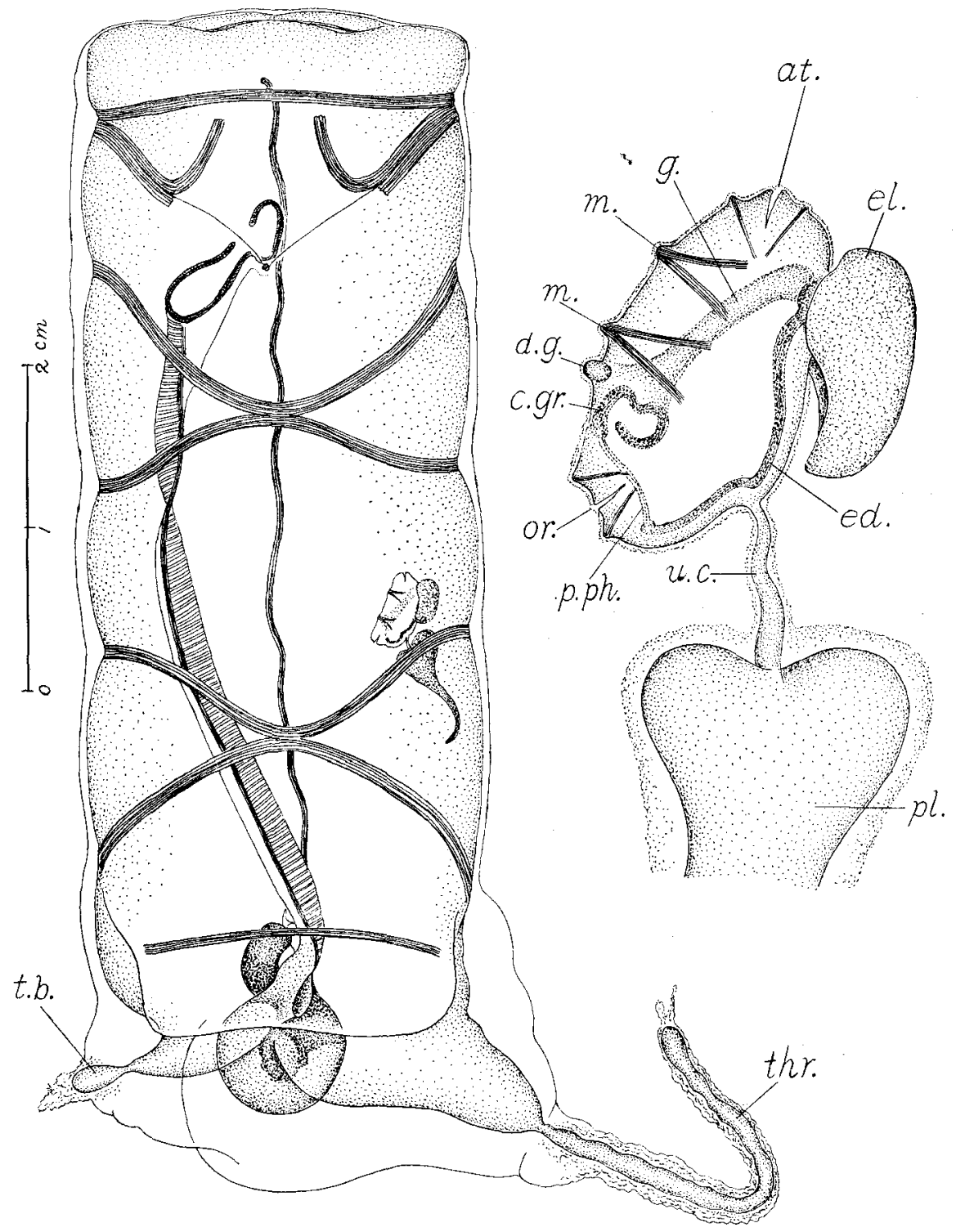

Fig. 2. Pegea confoederata bicaudata (Q. \& G.) greg. Left : No. 9 terminal individual. Right : Embryo with distal portion of placenta, enlarged. For captions see Fig. 1.

length. It is always covered with worn test, and sometimes bears a small piece of torn test at the distal end. On the long right protuberance of the terminal individuals, the portion corresponding to the terminal bulb assumes a thread of 20 to $27 \mathrm{~mm}$ in length (Fig. $2 \mathrm{thr}$.). This bulb-like structure of the posterior protuberances may indicate a possible process of shortening of the 
protuberance by successive wearing off of the distal end of the protuberance. Thus, the terminal bulb may represent a phase of this reduction process. Possibly the posterior protuberances of most individuals were once considerably longer. In more advanced stages all terminal bulbs of all individuals throughout the whole chain, including the thread-like distal portion of the right protuberance of terminal individuals, would be quite torn or pinched off and all individuals would be equally provided with a pair of very short protuberances.

Finally the existence of tremendously long right protuberances and then the remarkable inequality of the posterior protuberances seen on both terminal

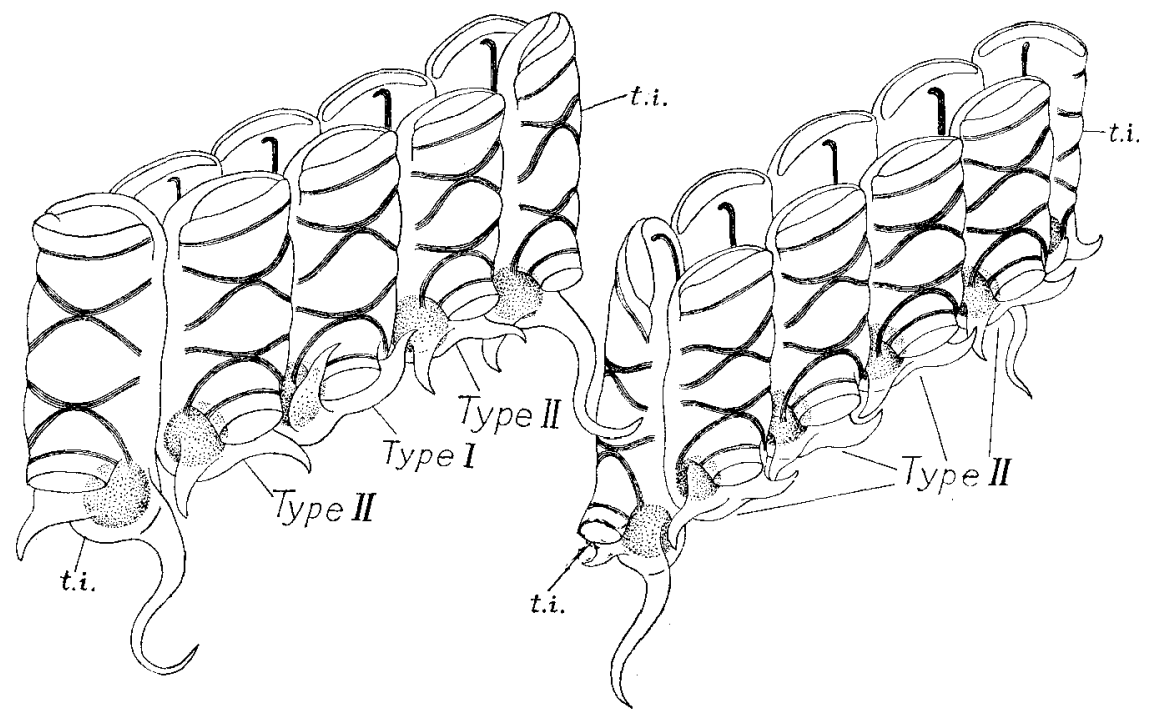

Fig. 3. Pegea confoederata bicaudata (Q. \& G.) greg. Possible arrangements of chain individuals. Left : Types of posterior protuberances reflecting the relation of space between individuals, but not related to the sinistral and dextral situation of individuals. Right: Types of protuberances are related to the sinistral and dextral situation of individuals. t. $i$--terminal individual.

individuals will be discussed. These might be merely aspects that occurred in a quite casual way, such as an injury. But, if the chain retained the same arrangement of the individuals throughout its development to the present size, with embryos $4 \mathrm{~mm}$ long, it is not impossible that the terminal individuals were modified differently from other chain individuals by some biological mechanism as seen on terminal cells of some species of chain diatoms, such as Chaetoceros. If chain individuals retain some organic connection to one another through their attachment processes, then the supposition of some polarity acting throughout the chain may be easily accepted. In reality, however, it is not likely that any organic connection is retained between 
chain individuals, although some connection must be retained throughout the whole chain of individuals in the very early stages of chain formation on the stolon. If the chain were released from the stolon in the stage when some organic connection between individuals was still retained and if the polarity printed on terminal individuals in the earlier stage of liberation continued to work on after the organic connection between individuals was cut off, then the differentiation of terminal individuals might be due to that mysterious polarity.

On the other hand, it is very possible, too, that the special morphology of terminal individuals was caused by some simple physical effect such as difference of space, because the terminal individual commands much more space than other chain individuals.

So definite a difference seen between the terminal individuals and other chain individuals and the regular prolongation of only the right protuberance on terminal individuals seem to tempt us to imagine some genetic mechanism producing such a differentiation. Very probably the prolongation of only the right protuberance is an aspect of the primary asymmetry. 